NBER WORKING PAPER SERIES

ON THE NEGATIVE CORRELATION

BETWEEN PERFORMANCE AND

EXPERIENCE AND EDUCATION

\author{
Andrew Weiss \\ Henry Landau
}

Working Paper No. 1613

NATIONAL BUREAU OF ECONOMIC RESEARCH

1050 Massachusetts Avenue

Cambridge, MA 02138

April 1985

The research reported here is part of the NBER's research program in Labor Studies and project in Productivity and Industrial Change in the World Economy. Any opinions expressed are those of the authors and not those of the National Bureau of Economic Research. 


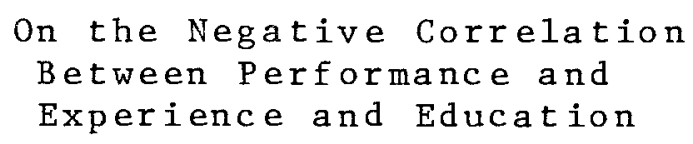

We consider a model where a worker's productivity must exceed some lower bound for him to satisfy the minimum qualifications for a particular job. If the worker's productivity exceeds some upper bound he is promoted. We assume the productivity of every worker increases with experience, tenure and education. This relationship differs across workers.

We present distributions of workers with the property that, among workers on a particular job, education, experience, or tenure is negatively correlated with productivity; even though for any single worker on that job these demographic characteristics have strongly positive effects on productivity. The result is due to the effect of the job assignment rule on the distribution of workers on the job.

Andrew Weiss

Department of Economics

Columbia University

New York, NY 10027
Henry Landau

AT\&T Bell Laboratories

600 Mountain Avenue

Murray Hil1, NJ 07974 


\section{On the Negative Correlation between \\ Performance and Experience and Education*}

by

Andrew Weiss

Columbia University, Bell Communications Research, and N.B.E.R

Henry J. Landau

AT\&T Bell Laboratories

\section{INTRODUCTION}

It is a commonplace observation that while earnings generally increase with age, labor market experience, and education, performance within a job often decreases with age, experience and education. (See for example, Medoff and Abraham, Berg, Kutscher and Walker, or Clay.)

One reason for this apparent divergence between performance and earnings is that the distribution of workers on a job is generally truncated from above and below: there are usually hiring criteria that applicants must satisfy to be assigned to that job (or to keep it), and there are usually also promotion criteria. Since measures of productivity within a job are necessarily restricted to workers who were assigned to those jobs and have not yet been promoted (or demoted), there is a clear sample-selection bias operating. For example, Medoff and Abraham (1980a) find in an empirical study that better educated workers need to achieve a lower level of productivity before being promoted than do less well

* The opinions expressed are not necessarily those of AT\&T Bell Laboratories, of Bell Communication Research, or of NBER. 
educated workers. ${ }^{1}$ Hence, even if productivity were positively correlated with education we could find that the better educated within a job (those who haven't been promoted) are, on average, less productive than the less well educated workers.

In this paper we prove a stronger point. Suppose job assignments were determined solely by productivity (so that the same level of performance were required for each worker's promotion) and productivity were an increasing function of experience and education. The use of productivity as the sole criterion for promotions could still cause a negative correlation between productivity and experience (or education) within jobs. The reason is that although the productivity of each individual increases with experience, the distribution of people by innate ability changes across experience and education bands within a job. The lower innate ability of the more experienced and better educated workers on a job could outweigh the direct effect of experience and education on their performance, and cause a negative correlation between experience (or education) and performance on that job.

Our argument is based on a model in which productivity is linked to job assignment. Such a linkage is explicitly formulated in models by Calvo and Wellisz, Rosen, and Guasch and Weiss.

1. This could be explained if some of the learning in school has a greater effect on productivity in higher level jobs than in lower level ones. 
In the Calvo-Wellisz model, shirking by supervisors is more harmful to the firm than is shirking by production workers. Consequently the more able workers are assigned to supervisory positions and are paid more (to increase their effort).

In the Rosen model, the production technology of the firm amplifies the productivity of supervisors relative to that of production workers. The output of supervisors affects the output of their subordinates. In equilibrium, the most productive, and most highly paid, workers are assigned jobs higher up in the corporate hierarchy.

In the Guasch-Weiss model, promotions of the more able workers are used as sorting mechanisms to induce applications from workers of high ability.

\section{THE MODEL}

Assume a continuous distribution $F(i)$ of individuals $i \in R^{+}$in the population, and denote $F^{\prime}(i)$ by $f(i)$. The productivity of an individual $i$ is $i x$ where $x$ represents either experience or education (for ease of exposition we shall refer to $x$ as experience). Thus we are assuming that, for every individual, productivity increases with $x$. We are concerned with the relationship between productivity and experience on a particular job. Workers need a productivity of $r$ to be assigned to this job. When their productivity exceeds $s$ they are promoted. Consequently, the individuals with total labor market experience $x$ who have this job are represented by the band of abilities $i$ for which

$$
r \leqslant x i \leqslant s .
$$


We also allow for the possibility that the individual learns something on the job that enhances productivity there, but not on other jobs. Let $y$ be the time on the job. Since, according to (1), the job begins when $x=r / i$, and ends when $x=s / i$, we have

$$
\begin{gathered}
y=x-r / i, \\
0 \leqslant y \leqslant(s-r) / i .
\end{gathered}
$$

We assume that productivity on the job for individuals of type $i$ is given by

$$
i x+\alpha i y,
$$

for some constant $\alpha$. If $\alpha=0$, there is no job-specific learning. To put this in terms of the variable $x$, we substitute for $y$ from (2), obtaining

$$
i x+\alpha i y=x(1+\alpha) i-\alpha r,
$$

in which, by (1), $i$ is restricted to the range

$$
r / x \leqslant i \leqslant s / x
$$

It is this fact, that longer experience $x$ is associated with groups of lower ability, that we wish to stress here.

By (4) and (5), the average productivity, $A P(x)$, of workers on a particular job who have total work experience $x$, is 


$$
\begin{aligned}
A P(x) & \equiv \frac{\int_{x / x}^{s / x}[x(1+\alpha) i-\alpha r] f(i) d i}{\int_{r / x}^{s / x} f(i) d i} \\
& =(1+\alpha) \frac{x \int_{r / x}^{s / x} i f(i) d i}{\int_{r / x}^{s / x} f(i) d i}-\alpha r
\end{aligned}
$$

To show that this expression can decrease with increasing $x$ we need only produce an example. Suppose

$$
f(i)=\left\{\begin{array}{cl}
\frac{6}{5}\left[i^{-3}+i^{-4}\right] & , i \geqslant 1 \\
0 & , i<1,
\end{array}\right.
$$

and consider an experience cohort for which $r / x \geqslant 1$. Then we find

$$
\begin{aligned}
\frac{x \int_{r / x}^{s / x} i f(i) d i}{\int_{r / x}^{s / x} f(i) d i} & =x \frac{\left(\frac{x}{r}-\frac{x}{s}\right)+\frac{1}{2}\left(\frac{x^{2}}{r^{2}}-\frac{x^{2}}{s^{2}}\right)}{\frac{1}{2}\left(\frac{x^{2}}{r^{2}}-\frac{x^{2}}{s^{2}}\right)+\frac{1}{3}\left(\frac{x^{3}}{r^{3}}-\frac{x^{3}}{s^{3}}\right)} \\
& =\frac{1+\frac{x}{2}\left(\frac{1}{r}+\frac{1}{s}\right)}{\frac{1}{2}\left(\frac{1}{r}+\frac{1}{s}\right)+\frac{x}{3}\left(\frac{1}{r^{2}}+\frac{1}{r s}+\frac{1}{s^{2}}\right)}
\end{aligned}
$$




$$
\begin{aligned}
& =\frac{3\left(\frac{1}{r}+\frac{1}{s}\right)}{2\left(\frac{1}{r^{2}}+\frac{1}{r s}+\frac{1}{s^{2}}\right)}+\frac{6-\frac{9\left(\frac{1}{r}+\frac{1}{s}\right)^{2}}{2\left(\frac{1}{r^{2}}+\frac{1}{r s}+\frac{1}{s^{2}}\right)}}{3\left(\frac{1}{r}+\frac{1}{s}\right)+2 x\left(\frac{1}{r^{2}}+\frac{1}{r s}+\frac{1}{s^{2}}\right)} \\
& =\frac{3\left(\frac{1}{r}+\frac{1}{s}\right)}{2\left(\frac{1}{r^{2}}+\frac{1}{r s}+\frac{1}{s^{2}}\right)}+\frac{\frac{3\left(\frac{1}{r}-\frac{1}{s}\right)^{2}}{2\left(\frac{1}{r^{2}}+\frac{1}{r s}+\frac{1}{s^{2}}\right)}}{3\left(\frac{1}{r}+\frac{1}{s}\right)+2 x\left(\frac{1}{r^{2}}+\frac{1}{r s}+\frac{1}{s^{2}}\right)},
\end{aligned}
$$

the first reduction obtained by removing the common factor $x^{2}(1 / r-1 / s)$ from numerator and denominator, and the second by writing the result, $(A+B X) /(C+D x)$, in the form $B / D+(A-B C / D) /(C+D x)$. As the final expression decreases when $x$ increases, the average product of labor on the job is a decreasing function of total labor experience.

Thus for each individual, productivity increases with experience. However, in the job-experience cohort being selected, the more experienced workers are less productive.

Of course these results are sensitive to the distribution, $F(i)$, of ability in the population. For example, suppose that, within the relevant range of ability types, $f(i)=K i^{\beta}$, where $K$ is a constant of normalization. Then given our learning function and job assignment criterion, expected productivity within the job would be independent of experience. (This result follows trivially from substituting into (6)). Examples of distributions for which expected productivity increases with experience are likewise easy to find. 
As we already mentioned, this argument is directly applicable to the relationship between productivity and education: we need only change the definition of $x$. However, the relationship between productivity and experience can be different when the measure of experience is $y$, tenure on the job, rather than $x$, total work experience. By (2), expressing the productivity in terms of $y$ yields

$$
i x+\alpha i y=y(1+\alpha) i+r \text {, }
$$

where, by (3), $i$ is restricted to the range

$$
0 \leqslant i \leqslant(s-r) / y
$$

Here, because each year on the job contributes a year to total experience, observed tenure on a job places an upper bound on innate ability, for individuals with ability exceeding $(s-r) / y$ would have been promoted out of the job before attaining tenure $y$. On the other hand, tenure places no positive lower bound on the productivity of individuals. In our model a person of arbitrarily low innate ability could qualify for any job by dint of sufficiently long experience. On comparing (5) and (9), we see that, even within a given job, sorting workers by $x$ or by $y$ yields different ability groups. Consequently, average productivity on a job can vary differently with $y$ from how it varies with $x$. Indeed,

$$
\begin{aligned}
A P^{*}(y) & \equiv \frac{\int_{0}^{(s-r) / y}[y(1+\alpha) i+r] f(i) d i}{\int_{0}^{(s-r) / y} f(i) d i} \\
& =(1+\alpha) \frac{y \int_{0}^{(s-r) / y} \text { if }(i) d i}{\int_{0}^{(s-r) / y} f(i) d t}+r,
\end{aligned}
$$

and for the choice $f(i)$ of (7) this now increases in $y$. However, if $f(i)$ were a 
suitably scaled version of $\left(i+i^{2}\right)$, for $i$ in a finite range, average productivity would decrease as tenure on the job increases.

\section{DISCUSSION}

We have shown that sample selection can cause the measured relationship between particular worker characteristics and productivity on a job to be the reverse of what it actually is in the entire worker population. The distributions we have chosen to illustrate this do not seem unreasonable. Moreover, there is evidence that promotional criteria are less stringent for better educated workers, which would tend to strengthen the bias further.

We thus conclude that lower productivity of more experienced or educated workers within a job is consonant with human capital theory, which predicts that productivity of any worker increases with experience and education. 


\section{REFERENCES}

Becker, G., Human Capital, Chicago: University of Chicago Press, 2nd edition; 1975.

Belbin, R. M. "Difficulties of Older People in Industry" Occupational Psychology," 1953, 27, 177-190.

Birren, J. E. The Psychology of Aging, Englewood Cliffs N.J. Prentice Hall 1964.

Clay, H. M. "A Study of Performance in Relation to Age at Two Printing Works" Journal of Gerontology, 1956, 11, 417-424.

Berg, I. The Great Training Robbery: Columbia Univ. Press, 1973.

Freeman, S., "Wage Trends as Performance Displays Productive Potential: A Model and Application to Academic Early Retirement," The Bell Journal of Economics, Vol. 8, (Autumn 1977), 419-443.

Guasch, J. L. and A. Weiss, "An Equilibrium Analysis of Wage-Productivity Gaps", Review of Economic Studies, Vol. 49, (1982), 485-497.

Harris, M., and B. Holmstrom "A Theory of Wage Dynamics", Review of Economic Studies, Vol. 49, (July 1982), 315-333.

Holmstrom, B., "Equilibrium Long-term Contracts", The Quarterly Journal of Economics, Vol. 98, (Supplement 1983), 23-54.

Kutscher, R. E. and Walker, J. F. "Comparative Job Performances of Office Workers by Age", Monthly Labor Res., 1960, 83, 39-44.

Lazear, E., "Why is There Mandatory Retirement?" Journal of Political Economy, Vol 87, (December 1979), 1261-1284.

Lazear, E., "Agency, Earnings Profiles, Productivity and Hours Restrictions," American Economic Review, Vol. 71, (September 1981), 606-620.

Medoff, J., and K. Abraham, "Experience, Performance and Earnings," Quarterly Journal of Economics, Vol. 95, (December 1980), 703-736.

Medoff, J., and K. Abraham, "Are Those Paid More Really More Productive?" Journal of Human Resources, Vol 41, No 2, (Spring 1981), 186-216.

Mincer, J., Schooling Experience and Earnings, New York, NBER; 1974. 
Muriel, K. F. N. and Griew, S. "Age Experience and Speed of Response" In A. T. Welford and J. E. Birren, Behavior Aging and the Nervous System Springfield Illinois, Charles. C. Thomas 1965.

Rosen, S., "Authority, Control and the Distribution of Earnings," Bell Journal of Economics, Vol. 13, (Autumn 1982), 311-323.

Weiss, A. "Simple Truths of Japanese Manufacturing," Harvard Business Review, Vol 84, (July-August 1984), 119-125. 